\title{
Sublingual Misoprostol to Reduce Blood Loss at Cesarean Delivery
}

\author{
Sood Atul Kumar $\cdot$ Singh Sanjay
}

Received: 27 November 2009/Accepted: 2 April 2012/Published online: 1 June 2012

(C) Federation of Obstetric \& Gynecological Societies of India 2012

\begin{abstract}
Objective This prospective randomized controlled study was carried out with the purpose of assessing the efficacy of sublingual misoprostol in decreasing intraoperative blood loss and the need for additional uterotonic agents at cesarean delivery.

Methods One hundred seventy-four women undergoing elective or emergency cesarean delivery were assigned randomly to receive either $400 \mu \mathrm{g}$ misoprostol or placebo sublingually at the time of cord clamping. An intravenous infusion of 20 units of oxytocin was started in all women at the same time. The primary outcome measures were intraoperative blood loss, need for additional uterotonic agents, and perioperative hemoglobin $(\mathrm{Hb})$ fall.

Results The maternal demographic factors, indications for cesarean delivery, and high-risk factors were similar between the two groups. Mean intraoperative blood loss was significantly less in misoprostol group as compared with placebo group $(595 \pm 108$ vs. $651 \pm 118 \mathrm{ml}$, $P=0.025)$. Fewer women needed additional uterotonic agents in misoprostol group (22.2 vs. $42.8 \% ; P=0.0035$; RR $0.52,95 \%$ CI $0.33-0.82$ ). Perioperative $\mathrm{Hb}$ fall was
\end{abstract}

Sood A. K. ( $₫)$, Classified Specialist

Department of Obstetrics \& Gynecology, Armed Forces Clinic, New Delhi, Dalhousie Road, New Delhi 110011, India

e-mail: soodatulk@gmail.com

Singh S., Classified Specialist

Department of Obstetrics \& Gynecology, Military Hospital, Jalandhar, India significantly less in misoprostol group $(0.87 \pm 0.29$ vs. $1.01 \pm 0.26 \mathrm{~g}, P=0.0018$ ).

Conclusion Sublingual misoprostol decreases intraoperative blood loss and the need for additional uterotonic agents at cesarean delivery.

Keywords Sublingual misoprostol $\cdot$ Blood loss · Cesarean delivery

\section{Introduction}

Postpartum hemorrhage is the leading cause of preventable maternal mortality in the developing world, and its prevention is assumed to be an important and rational strategy, and has been identified as a key component of safe motherhood. Oxytocin is routinely used to prevent uterine atony and excessive uterine bleeding during cesarean delivery. However, despite its effectiveness, 10-40\% of women need additional uterotonic therapy $[1,2]$. Secondary uterotonic agents such as methyl ergometrine or 15-methyl prostaglandin $F_{2} \propto$ are associated with adverse effects when administered within a dose range likely to be effective.

Misoprostol is a prostaglandin E1 analogue with good uterotonic properties and few adverse effects at therapeutic dose. Because of its uterotonic properties, misoprostol has been evaluated for both the prevention and the treatment of postpartum hemorrhage [3]. It is readily absorbed when given by oral, sublingual, buccal, vaginal, or rectal route. Its easy availability, relatively low cost, thermo stability, 
long shelf life, and ease of administration, all of which appear to make it particularly suitable for use in low resource settings in developing countries.

Although misoprostol has been extensively evaluated for prevention and treatment of postpartum hemorrhage following vaginal delivery, there have been a few randomized controlled trials evaluating its efficacy in reducing intraoperative blood loss and additional uterotonic therapy at cesarean delivery. Misoprostol in these trials has been administered by oral, buccal, or sublingual routes and compared mostly with oxytocin administered as IM/IV bolus, IV infusion, or intrauterine injection or with placebo. Though dose of misoprostol used in these trials has widely varied, most of them found misoprostol as effective as $[1,5-8]$ and-in one case more effective than-oxytocin [4].

The present study was undertaken with the aim of assessing the efficacy of sublingual misoprostol in decreasing intraoperative blood loss and the need for additional uterotonic agents at cesarean delivery.

\section{Methods}

This prospective randomized placebo controlled trial was conducted at Military Hospital Jhansi, Uttar Pradesh. All women undergoing emergency or elective cesarean section were eligible for the study irrespective of indication, previous cesarean or high-risk factor. Informed consent was taken from all subjects. Women were assigned randomly to receive either $400 \mu \mathrm{g}$ misoprostol or placebo sublingually at the time of cord clamping. Randomization was by computer-generated random numbers and the randomized allocations were kept secure in sequentially numbered opaque, sealed envelopes made at pharmacy containing either $400 \mu \mathrm{g}$ misoprostol or placebo, which were opened in the operation room. At no time before the data analysis were the group assignments made available to anyone but the pharmacy.

All uterine incisions were low transverse type. At cord clamping, the medication was placed in the patient's sublingual space by the anesthesiologist. Simultaneously, for all women, an intravenous infusion of oxytocin $20 \mathrm{U}$ in $1,000 \mathrm{ml}$ saline solution was started at $10 \mathrm{ml} / \mathrm{min}$ for $30 \mathrm{~min}$, which was followed by $2.0 \mathrm{ml} / \mathrm{min}$ for $6 \mathrm{~h}$. Placenta was removed by controlled traction after spontaneous separation. Uterus was exteriorized after delivery of placenta, and all women received uterine massage. The surgeon requested additional uterotonic agents on the basis of the clinical findings during surgery. At the discretion of the obstetrician, additional oxytocin was added to the standard oxytocin infusion before secondary uterotonic agents were requested. Additional oxytocin was considered additional uterotonic intervention for purposes of data analysis. Inj Methyl ergometrine $0.2 \mathrm{mg}$ IM and Inj 15-methyl prostaglandin $\mathrm{F}_{2} \propto 250 \mu \mathrm{g}$ IM were used as secondary uterotonic agents.

Uterine incision was closed in two layers with No 1 polyglactin. Visceral and parietal peritoneum was not closed. Rectus sheath was approximated with No 1 polypropylene. Skin was approximated with subcuticular closure. Prophylactic antibiotic Inj Cefazolin $2.0 \mathrm{~g}$ IV was given at cord clamping, except in women already on antibiotics.

The primary outcome measures were intraoperative blood loss and the need for additional uterotonic agents and perioperative hemoglobin $(\mathrm{Hb})$ fall. Secondary outcome measures were shivering, pyrexia, nausea, vomiting, operating time, postpartum hemorrhage, blood transfusion, endomyometritis, and hospitalization period.

Intraoperative blood loss was calculated by measuring blood in the suction apparatus and sterile drapes before irrigation and by evaluating the blood in abdominal swabs and gauzes. Additional uterotonic therapy included additional oxytocin requirement or the use of secondary uterotonic agents. Perioperative fall in $\mathrm{Hb}$ was calculated from preoperative and second postoperative days' $\mathrm{Hb}$ estimation.

Pyrexia was defined as temperature more than $38.0^{\circ} \mathrm{C}$. Postpartum hemorrhage was defined as estimated loss of at least 1,000 ml. Endomyometritis was diagnosed if uterine tenderness and fever were present. Operation time was abstracted from operation notes. The length of postoperative hospital stay was calculated from medical records.

\section{Statistical Methods}

A sample size and power analysis were undertaken before study. Ninety women were required in each arm to show a reduction in additional uterotonic therapy from 40 to $20 \%$ with misoprostol (Power $=0.80, \alpha=0.05$ and $\beta=0.2$ ). Based on estimated blood loss in women during cesarean section, taking mean blood loss $650 \mathrm{ml}$ with a SD of $120 \mathrm{ml}, 88$ women were required in each arm to show a reduction of blood loss of $50 \mathrm{ml}$ with misoprostol (Power $=0.80, \alpha=0.05$ and $\beta=0.2$ ). Student's unpaired $\mathrm{t}$ tent was used for analysis of continuous variables. Categorical variables were analyzed by Chi square test or Fisher exact test if numbers were small. $P<0.05$ was considered as the level of significance. Relative risk (RR) and $95 \%$ confidence intervals $(95 \% \mathrm{CI})$ were calculated for categorical data. Statistical software Epi Info Version 3.2.2 (Center for Disease Control and Prevention Atlanta, Georgia, USA) was used for statistical analysis of data.

\section{Results}

From June 2003 to July 2005, a total of 174 women were recruited for the study. Ninty were randomly assigned to 
misoprostol group and 84 to placebo group. All women received allocated intervention, completed follow up and were analyzed according to group assignment. There was no significant difference between two groups with respect to age, parity, gestational age, and preoperative $\mathrm{Hb}$. Both groups were also similar with respect to primary/repeat or elective/emergency cesarean section or the type of anesthesia (Table 1). There was no difference between two groups with respect to the indication for cesarean section or various high-risk factors (Tables 2, 3).

Mean intraoperative blood loss was significantly less in misoprostol group as compared to placebo $(595 \pm 108$ vs. $651 \pm 118 \mathrm{ml}, P=0.025$ ). Proportion of women with blood loss between 500 and $1,000 \mathrm{ml}$ was lesser with misoprostol. (74.4 vs. $87.0 \%, P=0.038$, RR $0.86,95 \%$ CI 0.74-0.99) However, there was no difference in proportion of women with blood loss of $1,000 \mathrm{ml}$ or more or the need for blood transfusion. Fewer women in misoprostol group needed additional uterotonic agents in misoprostol group (22.2 vs. $42.8 \% ; P=0.0035$; RR 0.52 , $95 \%$ CI $0.33-0.82$ ). Mean postoperative $\mathrm{Hb}$ (g) was significantly higher in the misoprostol group $(9.79 \pm 0.99$ vs. $9.51 \pm 0.56, P=0.023)$. Perioperative $\mathrm{Hb}$ fall was significantly less in misoprostol group $(0.87 \pm 0.29$ vs. $1.01 \pm 0.26 \mathrm{~g}, P=0.0018$ ). Perioperative $\mathrm{Hb}$ fall of $1 \mathrm{~g}$ or more was lesser in misoprostol group (64.4 vs. $86.9 \%$, $P=0.00059$, RR 0.74, $95 \%$ CI 0.62-0.88) (Table 4).

Shivering was significantly more with misoprostol (21.1 vs. $9.5 \%, P=0.034$, RR $2.22,95 \%$ CI 1.03-4079). However, there was no significant difference in incidence of pyrexia, nausea, or vomiting. Similarly, there was no difference in endomyometritis or hospitalization period (Table 5).
Table 2 Indications for cesarean delivery

\begin{tabular}{llll}
\hline Data: number (percentage) & & \\
\hline & $\begin{array}{l}\text { Misoprostol } \\
(N=90)\end{array}$ & $\begin{array}{l}\text { Placebo } \\
(N=84)\end{array}$ & $P$ \\
\hline Post cesarean & $26(28.9)$ & $22(26.2)$ & NS, $P=0.69$ \\
Dystocia & $23(25.6)$ & $18(21.4)$ & NS, $P=0.52$ \\
Fetal distress & $15(16.7)$ & $16(19.0)$ & NS, $P=0.68$ \\
Breech & $14(15.6)$ & $14(16.7)$ & NS, $P=0.84$ \\
Others & $12(13.2)$ & $14(16.7)$ & NS, $P=0.54$ \\
\hline
\end{tabular}

Values in parentheses indicate percentage

None of the differences was significant

$S$ Significant, NS Not significant

\section{Discussion}

Cesarean section is the most common major operation performed on women worldwide. Despite routine use of oxytocin during cesarean delivery, a number of women especially those at high risk may develop uterine atony and hemorrhage either during surgery or in the immediate postoperative period, with serious consequences. Any modality of treatment which helps in its prevention will be useful in reducing maternal mortality and morbidity. Misoprostol is an evidence-based alternative to other uterotonic agents which require a cold chain, skilled administration, and have untoward effects in therapeutically effective doses. Further, the drug's wide availability, low-cost, stability at room temperature, and ease of use make it an ideal drug for use in such settings.

Zhao et al. [4] in their study comparing $600 \mu \mathrm{g}$ oral misoprostol with oxytocin (20 U intrauterine plus $20 \mathrm{U} \mathrm{IV}$ )
Table 1 Maternal demographics and procedure statistics

All differences were not significant

$S$ Significant, NS Not significant

${ }^{\text {a }}$ Mean $\pm \mathrm{SD}$, Values in

parentheses indicate percentage

\begin{tabular}{llll}
\hline Data: mean $\pm \mathrm{SD}$ or number (percentage) & & \\
\hline & $\begin{array}{l}\text { Misoprostol } \\
(N=90)\end{array}$ & $\begin{array}{l}\text { Placebo } \\
(N=84)\end{array}$ & $P$ \\
\hline Maternal age $(\mathrm{yr})$ & $26.0 \pm 4.3^{\mathrm{a}}$ & $25.5 \pm 3.6$ & $\mathrm{NS}, P=0.36$ \\
Parity & $2.0 \pm 0.8^{\mathrm{a}}$ & $1.9 \pm 0.6$ & $\mathrm{NS}, P=0.45$ \\
Gestational age $(\mathrm{wk})$ & $38.2 \pm 1.6^{\mathrm{a}}$ & $37.7 \pm 1.9$ & $\mathrm{NS}, P=0.06$ \\
Preoperative $\mathrm{Hb}(\mathrm{g} / \mathrm{dl})$ & $10.67 \pm 0.90^{\mathrm{a}}$ & $10.53 \pm 0.49$ & $\mathrm{NS}, P=0.19$ \\
Cesarean & & $53(63.0)$ & $\mathrm{NS}, P=0.51$ \\
Primary & $61(67.8)$ & $31(37.0)$ & \\
Repeat & $29(32.2)$ & $58(69.0)$ & $\mathrm{NS}, P=0.43$ \\
Cesarean & & $26(31.0)$ & \\
Emergency & $57(63.3)$ & & $\mathrm{NS}, P=0.67$ \\
Elective & $33(36.7)$ & $78(92.8)$ & \\
Anesthesia & & $06(7.2)$ & \\
Spinal & $85(94.4)$ & & \\
Epidural & $05(5.6)$ & & \\
\hline
\end{tabular}


Table 3 High-risk factors

Values in parentheses indicate percentage

None of the differences was significant

$S$ Significant, $N S$ Not significant

Table 4 Operative factors

$S$ Significant, $N S$ Not significant

${ }^{\text {a }}$ Mean $\pm \mathrm{SD}$, Values in parentheses indicate percentage

Table 5 Perioperative morbidity

\footnotetext{
$S$ Significant, NS Not significant

${ }^{a}$ Mean $\pm \mathrm{SD}$, Values in parentheses indicate percentage
}

\begin{tabular}{llll}
\hline Data: number (percentage) & & & \\
\hline & $\begin{array}{l}\text { Misoprostol } \\
(N=90)\end{array}$ & $\begin{array}{l}\text { Placebo } \\
(N=84)\end{array}$ & $P$ \\
\hline Previous cesarean & $26(28.9)$ & $22(26.1)$ & $\mathrm{NS}, P=0.69$ \\
Induced/augmented labor & $23(25.5)$ & $27(32.1)$ & $\mathrm{NS}, P=0.34$ \\
Hypertensive disorders & $15(16.7)$ & $10(11.9)$ & $\mathrm{NS}, P=0.37$ \\
Premature rupture of membranes & $15(16.7)$ & $18(21.4)$ & $\mathrm{NS}, P=0.42$ \\
Chorioamnionitis & $06(6.6)$ & $04(4.8)$ & $\mathrm{NS}, P=0.74$ \\
Antepartum hemorrhage & $05(5.6)$ & $03(3.7)$ & $\mathrm{NS}, P=0.72$ \\
\hline
\end{tabular}

\begin{tabular}{|c|c|c|c|c|}
\hline \multicolumn{5}{|c|}{ Data: mean \pm SD or number (percentage) } \\
\hline & $\begin{array}{l}\text { Misoprostol } \\
(N=90)\end{array}$ & $\begin{array}{l}\text { Placebo } \\
(N=84)\end{array}$ & $P$ & $\mathrm{RR}(95 \% \mathrm{CI})$ \\
\hline \multicolumn{5}{|l|}{ Estimated Blood Loss } \\
\hline Total (ml) & $595 \pm 108^{\mathrm{a}}$ & $651 \pm 118^{\mathrm{a}}$ & $\mathrm{S}, P=0.0015$ & \\
\hline$<500 \mathrm{ml}$ & $17(18.9)$ & $07(8.3)$ & $\mathrm{S}, P=0.044$ & $2.27(0.99-5.19)$ \\
\hline $500-1,000 \mathrm{ml}$ & $67(74.4)$ & $73(87.0)$ & $\mathrm{S}, P=0.038$ & $0.86(0.74-0.99)$ \\
\hline$>1,000 \mathrm{ml}$ & $06(6.7)$ & $04(4.7)$ & NS, $P=0.748$ & $1.40(0.41-4.79)$ \\
\hline Additional uterotonic therapy & $20(22.2)$ & $36(42.8)$ & $\mathrm{S}, P=0.0036$ & $0.52(0.33-0.82)$ \\
\hline Blood transfusion & $03(3.3)$ & $02(2.4)$ & $\mathrm{NS}, P=1.00$ & $1.40(0.24-8.17)$ \\
\hline Postoperative $\mathrm{Hb}(\mathrm{g} / \mathrm{dl})$ & $9.79 \pm 0.99$ & $9.51 \pm 0.56$ & $\mathrm{~S}, P=0.023$ & \\
\hline \multicolumn{5}{|l|}{ Perioperative $\mathrm{Hb}$ fall } \\
\hline $\mathrm{g} / \mathrm{dl}$ & $0.87 \pm 0.29$ & $1.01 \pm 0.26$ & $\mathrm{~S}, \mathrm{P}=0.0016$ & \\
\hline $1.0 \mathrm{~g} / \mathrm{dl}$ or more & $58(64.4)$ & $73(86.9)$ & $\mathrm{S}, P=0.00059$ & $0.74(0.62-0.88)$ \\
\hline Operating time (min) & $32.98 \pm 6.9$ & $32.03 \pm 4.24^{\mathrm{a}}$ & $\mathrm{NS}, P=0.23$ & \\
\hline
\end{tabular}

\begin{tabular}{lllll}
\hline Data: mean \pm SD or number (percentage) & & & \\
\hline & $\begin{array}{l}\text { Misoprostol } \\
(N=90)\end{array}$ & $\begin{array}{l}\text { Placebo } \\
(N=84)\end{array}$ & $P$ & RR (95\% CI) \\
\hline Shivering & $19(21.1)$ & $8(9.5)$ & $\mathrm{S}, P=0.034$ & $2.22(1.03-4079)$ \\
Pyrexia & $10(11.1)$ & $6(7.1)$ & NS, $P=0.365$ & $1.56(0.59-4.09)$ \\
Nausea & $10(11.1)$ & $8(9.5)$ & NS, $P=0.731$ & $1.17(0.48-2.82)$ \\
Vomiting & $5(5.6)$ & $3(3.6)$ & NS, $P=0.721$ & $1.56(0.38-6.31)$ \\
Hospitalization Period (days) & $6.71 \pm 0.83$ & $7.35 \pm 1.01$ & NS, P $=9.9$ & \\
\hline
\end{tabular}

found misoprostol more effective in the reduction of postpartum bleeding. Acharya et al. [1] comparing the effectiveness of $400 \mu \mathrm{g}$ oral misoprostol with $10 \mathrm{U}$ IV syntocinon found misoprostol to be as effective as intravenous syntocinon in the reduction of intraoperative blood loss. Lokugamage et al. [5] compared $500 \mu \mathrm{g}$ oral misoprostol with 10 U IV Syntocinon and concluded that oral misoprostol could be used as an alternative oxytocic agent. Hamm et al. [6] in a placebo controlled study concluded that $200 \mathrm{mcg}$ buccal misoprostol reduced the need for additional uterotonic agents. In another study comparing $400 \mu \mathrm{g}$ sublingual misoprostol versus $20 \mathrm{U}$ oxytocin infusion, Vimala et al. [7] found sublingual misoprostol to be as effective as oxytocin. In a placebo-controlled double blind study, comparing $800 \mu \mathrm{g}$ oral misoprostol with $20 \mathrm{U}$ oxytocin infusion after initial administration of $5 \mathrm{U}$ of IV oxytocin, Lapaire et al. [8] found misoprostol to be as effective as oxytocin in reducing postoperative blood loss.

The mean intraoperative blood loss in the present study was significantly less in misoprostol group, which is similar to that reported in two studies [4, 7]. However, some studies have reported no difference $[1,6,8]$. Blood loss at cesarean is difficult to assess accurately. In a study, visual assessment of blood loss was $33 \%$ less than the drape estimate; with the drape estimate correlating well with photo spectrometry [9]. In the present study to obviate the 
above limitation, perioperative change in $\mathrm{Hb}$ between preoperative and the second postoperative day was also done to assess the blood loss indirectly.

The need for additional uterotonic agents was significantly less in the present study; this finding is similar to that reported in a similar study in which oxytocin infusion was given to all women [6]. Some others have reported no difference $[1,7,8]$. IV Oxytocin injection appears in circulation within $15 \mathrm{~s}$ and reaches peak levels in $60 \mathrm{~s}$ with a half life of three min. Misoprostol appears in circulation within 20-30 min but stays longer. Thus, it may be useful to combine both drugs using IV oxytocin to achieve initial effect followed by misoprostol for more sustained effect. This may also be helpful in high-risk patients who are at increased risk of bleeding, but have contraindications for the use of secondary uterotonic agents [1].

Significant trend toward lesser perioperative $\mathrm{Hb}$ fall, which was found in this study, is similar to that reported in a recent study [10], in which concomitant oxytocin infusion was given to all women, as in the present study. In studies reporting no difference, misoprostol was either compared with oxytocin $[1,7,8]$, or a lower dose of misoprostol was used [6].

Shivering, pyrexia, nausea vomiting, and diarrhea are common adverse effects of misoprostol and are dose related. The increased incidence of shivering found in the present study is similar to that reported elsewhere [7]. However, there was no difference in pyrexia. No difference in other maternal adverse effects such as nausea or vomiting was noted, which is similar to that reported in the literature $[1,6,7]$.

Dose of misoprostol in various studies has ranged from 200 to $800 \mathrm{mcg}[1,4-8]$. As the side effects are dose related, a dose of $400 \mathrm{mcg}$ was chosen in the present study to minimize maternal adverse effects with optimal therapeutic benefit. In a recent review, $400 \mathrm{mcg}$ of misoprostol was found to be safer than $600 \mathrm{mcg}$ and just as effective [11].

Oral, buccal, rectal, and sublingual routes have been used in different studies. Sublingual route was chosen because it avoids oral intake, does not disrupt operative field, and ensures continuous plasma levels of a potent uterotonic agent over a prolonged period. Pharmacokinetic studies on various routes of administration have shown that sublingual route achieved the highest serum peak concentration (C max), the shortest time to peak concentration (T max), and the highest area under the curve (AUC) of misoprostol acid, the active metabolite of misoprostol [12-14].

In a Cochrane review on prostaglandins for prevention of postpartum hemorrhage, it was concluded that neither intramuscular prostaglandin nor misoprostol was preferable to conventional injectable uterotonics as part of the active management of the third stage of labor especially for lowrisk women [15]. However, in this meta-analysis which included 37 misoprostol trials, only three pertained to cesarean delivery. Misoprostol has been recommended in a dose of $600 \mathrm{mcg}$ or $400 \mathrm{mcg}$ by oral or sublingual route for prevention of PPH in the absence of active management of third stage of labor or non-availability of injectable conventional uterotonics $[16,17]$.

Cesarean delivery is carried out in a setting where conventional oxytocics are available and active management of third stage of labor is invariably practiced. Misoprostol may have a role as an adjunct to oxytocin in prevention of postpartum hemorrhage in high-risk women, where other uterotonic agents are either contraindicated or not available. In the present study, $400 \mathrm{mcg}$ by sublingual route appears to be promising. Two recent trials have confirmed efficacy of sublingual misoprostol in reducing blood loss at cesarean delivery $[10,18]$.

Post hoc power analysis showed that the present study (with an $\alpha$ of 0.05 ) had $78.9 \%$ power to detect reduction in uterotonic therapy from 42.8 to $22.2 \%$ and $92.5 \%$ power to detect a difference of mean blood loss of $56 \mathrm{ml}$. In the present study, sample size was relatively small. Blood loss estimated may not have true approximation of the actual loss. Though perioperative $\mathrm{Hb}$ fall was also studied, better methods involving measurement of actual blood loss may be more accurate. Larger studies with primary outcome measures such as incidence of postpartum hemorrhage and the need of blood transfusion are needed, to validate the efficacy of misoprostol and to find the optimal dose and route of administration at cesarean delivery.

\section{Conclusion}

Sublingual misoprostol reduces intraoperative blood loss and the need for additional uterotonic agents at cesarean delivery. It may have a role as an adjunct to oxytocin in the prevention of postpartum hemorrhage in high-risk women, where other uterotonic agents are either contraindicated or not available.

\section{References}

1. Acharya G, Al-Sammarai MT, Patel N, et al. A randomized, controlled trial comparing effect of oral misoprostol and intravenous syntocinon on intra-operative blood loss during cesarean section. Acta Obstet Gynecol Scand. 2001;80:245-50.

2. Munn MB, Owen J, Vincent R, et al. Comparison of two oxytocin regimens to prevent uterine atony at cesarean delivery: a randomized controlled trial. Obstet Gynecol. 2001;98:386-90.

3. Goldberg AB, Greenberg MB, Darney PD. Misoprostol and pregnancy. N Engl J Med. 2001;344:38-47. 
4. Zhao Y, Li X, Peng Y. Clinical study on reduction of postpartum bleeding in cesarean section by misoprostol. Zhonghua Fu Chan Ke Za Zhi. 1998;33:403-5.

5. Lokugamage AU, Paine M, Bassaw-Balroop K, et al. Active management of the third stage at caesarean section: a randomised controlled trial of misoprostol versus syntocinon. Aust N Z J Obstet Gynaecol. 2001;41:411-4.

6. Hamm J, Russell Z, Botha T, et al. Buccal misoprostol to prevent hemorrhage at cesarean delivery: a randomized study. Am J Obstet Gynecol. 2005;192:1404-6.

7. Vimala N, Mittal S, Kumar S. Sublingual misoprostol versus oxytocin infusion to reduce blood loss at cesarean section. Int $\mathbf{J}$ Gynaecol Obstet. 2006;92:106-10.

8. Lapaire O, Schneider MC, Stotz M, et al. Oral misoprostol versus intravenous oxytocin in reducing blood loss after emergency cesarean delivery. Int J Gynaecol Obstet. 2006;95:2-7.

9. Patel A, Goudar SS, Geller SE, et al. Drape estimation versus visual assessment for estimating postpartum hemorrhage. Int J Gynaecol Obstet. 2006;93:220-4.

10. Fekih M, Jnifene A, Fathallah K, et al. Benefit of misoprostol for prevention of postpartum hemorrhage in cesarean section: a randomized controlled trial [Article in French]. J Gynecol Obstet Biol Reprod. 2009;38:588-93.

11. Hofmeyr GJ, Gülmezoglu AM, Novikova N, et al. Misoprostol to prevent and treat postpartum hemorrhage: a systematic review and meta-analysis of maternal deaths and dose-related effects. Bull World Health Organ. 2009;87:666-77.

12. Tang OS, Schweer H, Seyberth HW, et al. Pharmacokinetics of different routes of administration of misoprostol. Hum Reprod. 2002;17:332-6.

13. Schaff EA, DiCenzo R, Fielding SL. Comparison of misoprostol plasma concentrations following buccal and sublingual administration. Contraception. 2005;71:22-5.

14. Tang OS, Gemzell-Danielsson K, Ho PC. Misoprostol: pharmacokinetic profiles, effects on the uterus and side-effects. Int $\mathbf{J}$ Gynaecol Obstet. 2007;99:S160-7.

15. Gülmezoglu AM, Forna F, Villar J, et al. Prostaglandins for prevention of postpartum hemorrhage. Cochrane Database Syst Rev. 2007;Issue 3, Art No: CD000494. doi: 10.1002/14651858.

16. Alfirevic Z, Blum J, Walraven G, et al. Prevention of postpartum hemorrhage with misoprostol. Int J Gynaecol Obstet. 2007. S198-201.

17. World Health Organization. WHO recommendations for the prevention of postpartum hemorrhage. Geneva: World Health Organization; 2007. p. 40. WHO/MPS/07.06.

18. Eftekhari N, Doroodian M, Lashkarizadeh R. The effect of sublingual misoprostol versus intravenous oxytocin in reducing bleeding after caesarean section. J Obstet Gynaecol. 2009;29: 633-6. 